\title{
The Curse and Blessing of Fixed Specific Factors in Small-Open Economies
}

\author{
María Dolores Guilló* \\ Fidel Perez-Sebastian* \\ guillo@merlin.fae.ua.es \\ fidel@merlin.fae.ua.es
}

December 2004

\begin{abstract}
This paper investigates how a country's specific-factors endowment affects its long-run economic performance. We build an open-economy version of the twosector neoclassical growth model in which we introduce fixed industry-specific inputs in both activities. We show that differences in input shares between sectors can contribute to explain why nations that seem to have similar factor endowments can show very different income levels. In particular, under (productivity-adjusted) factor-price equalization, larger amounts of factors specific to the industry with a lower (larger) labor share lead the economy to enjoy larger (smaller) long-run income levels. The model can also account for overtaking episodes between countries along their development paths.
\end{abstract}

JEL Classification: O41, F43.

Key words: Small-Open Economy, Specific-Inputs, Long-Run Income.

* Postal address: Universidad de Alicante, Departamento de Fundamentos del Análisis Económico, Campus de San Vicente, 03690 Alicante, Spain. This research was partially supported by the Spanish Ministry of Science and Technology, BEC2001-0535 and BEC2001-0980. The authors thank Jordi Caballé, Chris Papageorgiou, seminar participants at the ESEM 2003 in Stockholm, and two anonymous referees for useful comments. 


\section{Introduction}

This paper introduces fixed specific factors into an open-economy version of the standard two-sector neoclassical growth model. The main contribution of the paper is to provide conditions under which a larger endowment of an industry-specific factor has negative effects and conditions under which it has positive effects on a country's long run income level. The paper can therefore explain why some nations that seem to have similar endowments can show very different income levels. Our hypothesis is that one source of this difference can lie in the input intensities displayed by the industries to which these factors are specific.

The importance of industry-specific factors has been recognized at least since the work of Ricardo (1871). ${ }^{1}$ However, their impact on long run income and growth is not yet well understood. To illustrate this, take the example of a very important set of specific factors: the natural resources. These include land in agriculture, large bodies of water and coal in energy generation, and all kinds of minerals in their respective extractive industries. There is puzzling empirical evidence on the relationship between the natural-resource endowment and a nation's economic performance. On the one hand, we observe that large factor endowments can sometimes be a curse in terms of income. For instance, along history, resource-poor economies such as the Netherlands and Japan outperformed resource-rich nations such as Spain and Russia. Nowadays, most Asian tigers are resource-poor, whereas growth losers such as Nigeria, Zambia, Sierra Leone, and Venezuela are resource-rich. Gylfason (2001) and Sachs and Warner (2001) also argue that resource abundant countries lag, on average, behind countries with less resources. On the other hand, natural-input abundance seems to be a blessing some other times. World Bank (1994) finds at least five nations that belong to both the top eight regarding natural capital wealth and the top fifteen regarding per capita income.

Solving this puzzle is important for several developing countries, such as the ones in the middle East and Latin America, where the discovery of natural resources has

\footnotetext{
${ }^{1}$ Recent evidence finds also support for the specific-factors model of international trade. Kohli (1993) reports estimates of the specific factors and the Heckscher-Ohlin models of international trade for the US economy and finds that the former performs better than the latter, although US data display quite systematically some properties which are more in line with a Heckscher-Ohlin production structure. Rassekh and Thompson (1997) point out as well that a world in which each sector has some specific factor is at least as likely as one in which all inputs can freely move across activities. For differences between the Heckscher-Ohlin model and the standard specific-factors model of international trade, see for example Jones and Neary (1988).
} 
been considered as a positive precondition for more growth. Premise that, in light of the existent evidence, is not at all guaranteed.

We study a world economy where the production structure consists of the twosector neoclassical growth model with consumption and investment goods, in the tradition of Oniki-Uzawa (1965), in which the different industries have different input intensities. Firms in both sectors employ product-specific factors. There is also an alternative technology to produce investment goods that only requires mobile resources. Population is constant and consists of identical infinitely-lived agents. A small open economy shares preferences and technologies with the rest of the world but it can have different specific-factors endowments. As a result of this specification the model exhibits both Heckscher-Ohlin and specific-factors properties.

The paper shows that differences in input shares across activities can represent a key element in explaining the effect of specific-factor endowments on a small-open nation's economic performance. More specifically, larger amounts of inputs that are specific to an activity with a relatively large capital share lead the small nation to enjoy higher long-run welfare levels. On the contrary, larger stocks of factors that are specific to the less capital intensive sector have a negative influence on capital accumulation. This negative influence can totally offset the positive effect of the larger specific-factor endowment and lead the economy to permanently lower income levels if the technology to which this input is specific possesses a larger labor share than the technology that frees labor as a consequence of the increase in the specific-factor. The negative effect, on the other hand, disappears if the small country specializes in the production of one good. Under specialization, a larger endowment always raises long-run capital and output. The model predicts as well overtaking episodes between small open economies along their development paths.

The impact on long-run aggregate output of a rise in a factor specific to a more (less) labor intensive sector is always negative (positive) when international factor price equalization (FPE) holds. Although the empirical validity of the FPE is mixed, it has recently found considerable support. Trefler (1993) shows that a weak form of the FPE theorem that allows for factor-augmenting productivity differences is empirically consistent with observed cross-country variation in factor prices. This is the type of FPE that the model obtains in the long run. It obtains it because it incorporates an industry that only employs the accumulable factor and intersectorally mobile inputs. When this technology is used, its factor intensities determine the wage 
rate as a function of the long-run rental price of capital that, in Ramsey-type models, is pinned down solely by the international relative price of commodities and the common subjective discount factor. We also show that FPE is not necessary for a larger natural endowment to generate a negative impact on long run income, although it makes the existence of this perverse effect more likely.

The concern on the possibility of negative real income effects arising from an augmented resource is an old issue in development economics. The literature has already identified at least two channels through which an increase in a specific factor affects the allocation of resources and lead to a decrease in income. The first one operates through changes in international prices. In particular, the extensive literature on immiserizing growth or on the structural problems arising from a discovery of a natural resource (the called 'Dutch disease') shows that the possibility of a negative effect on income arises when either the terms of trade deteriorate or the real exchange rate worsens. ${ }^{2}$ This effect is ruled out in our model because international prices remain constant due to the small-country assumption. Second, there can be a technology channel that operates through differences in the overall efficiency level. For example, Matsuyama (1992) and Galor and Mountford (2002) emphasize that a larger natural endowment reduces the incentives to allocate resources to more growth-enhancing activities such as manufacturing and education, and therefore decreases long-run output. This mechanism is also absent in our model given that technological change is factor neutral and sector neutral.

Here, we point to the relevance of a third channel, driven by the small open economy assumption. Specific factors create differences in total factor productivity (TFP) across nations. Thus, ceteris paribus, a country with a higher level of a specific factor should have a higher income per capita, because of this TFP effect. However, unlike exogenous differences in TFP, an increase in a specific factor reallocates capital and labor from the rest of the economy to the sector to which the input is specific. This shift in resources affects the aggregate demand of labor and capital in a way that depends on input intensities. In a small-open economy for which the world's relative price is rigid, the latter Rybczynski effect implied by the augmented factor can reverse the positive TFP effect, and lead the economy to a lower long-run income level..$^{3}$

\footnotetext{
${ }^{2}$ See, for example, Eaton (1992) and Edwards and Van Wijnbergen (1992).

${ }^{3}$ This is in contrast to the predictions of closed-economy growth frameworks, in which an increase
} 
Our work is also related to dynamic international trade models that determine savings from utility maximization. Eaton (1987) is the first to take the Jones-Samuelson specific-factors model to a dynamic setting. He considers that land (a fixed factor) is used specifically in the production of one commodity, that capital (an accumulable resource) is the specific input in the production of the other commodity, and that labor is used commonly in both production activities. Except in a very special case, Eaton's (1987) model does not predict international FPE because of its overlapping generations structure. As in our model, a land abundant country can have a lower steady state welfare but under different and more restrictive conditions. ${ }^{4}$ Brock and Turnovsky (1993) use the same type of model as Eaton to study the impact of differential tariffs on welfare.

Markusen and Manning (1993) embed the Jones specific-factors model into a representative-agent framework to include the optimal accumulation of (one or two) specific inputs. They show, using a mechanism similar to ours, that the production structure in Eaton (1987) leads to FPE in the long-run with infinitely lived consumers. They, however, consider a less general production structure, and do not analyze the effects of larger endowments on long-run income.

The rest of the paper is organized as follows. Section 2 describes the economic environment. Section 3 studies the diversified production equilibrium of the world economy. Section 4 analyzes how the composition of the factor endowment affects the steady-state outcome of a small open economy, both qualitative and quantitatively. Section 5 discuses the results. Section 6 concludes.

\section{The world economy}

Consider a world where economic activity takes place over infinite discrete time. In every period, two goods are produced - a perishable consumption good and an investment good - using four inputs of production. The production of both the consumption

in a resource endowment affects relative prices, and always induces a positive effect on long-run capital and income. See, for example, Kögel and Prskawetz (2001), Hansen and Prescott (2002), Galor, Moav and Vollrath (2002), and Gollin, Parente and Rogerson (2002) that focus on the role of land in production.

${ }^{4}$ In the steady state, FPE holds in Eaton's (1987) model only when both sectors have identical labor shares in production. In that case, a land-abundant country can have a lower steady state level of capital, but the overall effect of land on long-run income is ambiguous. When FPE does not hold, a fall in steady state welfare from a larger natural resource endowment arises when the labor share of the land-using sector is lower than the labor share of the capital-using sector and the initial interest rate is high; but if the interest rate is initially low, more land always raises steady state welfare. 
and the investment commodities require the use of capital and labor inputs, which can freely move across sectors, and also of a third factor which is sector-specific. In addition, there exists a second technology to manufacture the investment good that only requires mobile inputs. ${ }^{5}$ All markets are perfectly competitive. Population is constant.

Specific factors are not produced and do not depreciate, their total amount is fixed over time. Given these special characteristics, we consider that specific factors are different types of natural resources. Some natural inputs such as land, large bodies of water, and renewed forests fulfill very well these features. Others, like copper, uranium and iron, are not produced but depreciate in the sense that they are depleted systematically. For these other natural inputs to be in fixed supply, their extraction level had to be constant; we assume this hereafter. ${ }^{6}$

We have two technologies that can produce the investment good, but only one of them requires a specific input. This assumption reflects that innovation has allowed to manufacture synthetic products that serve as good substitutes for some natural raw materials. An example is the rubber industry that manufactures inputs devoted, among other uses, to the production of electric insulation, tires, and containers. In this industry, some firms produce natural latex from rubber trees, a natural input that can not be employed for any other purpose; whereas other manufactures produce synthetic rubber from a variety of inputs such as petroleum derivatives that can be allocated as well to other activities. ${ }^{7}$

Infinitely-lived consumers discount future utility at rate $\beta$, and have preferences only over consumption. In particular, their preferences are given by

\footnotetext{
${ }^{5}$ As it will be clear later, this assumption has no impact on the main results of the paper. We could also consider two consumption-goods, one of them not requiring for its production a specific factor. This would not change our main results either.

${ }^{6}$ More generally, all inputs in some of their forms can be considered as specific factors. For example, following Ricardo's (1817) theory of rent and capital accumulation, Eaton (1987) looks at physical capital as an specific factor. Specialized labor can be also thought as an specific input, as in Dinopoulos and Sergerstrom (1999). Capital inputs, however, accumulate and are not in fixed supply. We leave incorporating these other type of specific factors for future research.

${ }^{7}$ An alternative interpretation is to think of the capital stock as a commodity composed of two different investment goods that, after being produced, become perfect substitutes. From this viewpoint, the industry that uses a specific factor could be, for example, a primary sector that extracts natural diamonds, or petroleum to produce derivatives such as thermoplastic resins. These primary goods would serve to augment the composite capital stock employed by all sectors in the economy, including the sector that produces the investment good using only capital and labor. In the real world, diamonds are used in jewelry as well as industrial production, and the industries that use thermoplastic resins include, among others, industrial machinery, packaging, and furniture.
} 


$$
\sum_{t=0}^{\infty} \beta^{t} \frac{c_{t}^{1-\sigma}-1}{1-\sigma}, \quad \beta \in(0,1), \quad \sigma>0 .
$$

Individuals offer labor services and rent capital and natural resources to firms. Natural resources in the economy are uniformly distributed across all individuals. The representative consumer faces the following budget constraint

$$
c_{t}+p_{t} x_{t}=r_{k t} k_{t}+r_{n c t}\left(\frac{N_{c}}{L}\right)+r_{n x t}\left(\frac{N_{x}}{L}\right)+w_{t},
$$

where the evolution of capital is governed by

$$
k_{t+1}=(1-\delta) k_{t}+x_{t}
$$

In the above expressions, $L$ represents the constant population size; $c_{t}$ is the per capita demand for consumption goods; $x_{t}$ is the per capita demand for investment goods, whose price is $p_{t} ; r_{k t}, r_{n c t}, r_{n x t}$, and $w_{t}$ are, respectively, the rental rates of capital, the consumption-goods specific factor, the investment-goods specific factor, and labor; $N_{c}$ and $N_{x}$ denote natural inputs specific to consumption-goods production and investment-products manufacturing, respectively; and $k_{t}$ is the capital stock own by the consumer at date $t .^{8}$ The consumption good is the numeraire.

The representative consumer will maximize (1) subject to (2) and (3), taking as given the world output prices and the domestic rental rates for production factors. The Euler equation corresponding to this dynamic programing problem is

$$
\frac{c_{t+1}}{c_{t}}=\left[\frac{p_{t+1}}{p_{t}} \beta\left(\frac{r_{k t+1}}{p_{t+1}}+1-\delta\right)\right]^{1 / \sigma} .
$$

It is standard. It says that the growth rate of consumption depends on the presentutility value of the rate of return to saving. This return reflects that giving up a unit of present consumption allows today buying $1 / p_{t}$ units of the investment goods that, after contributing to the production process, will covert themselves tomorrow in $1+r_{k t+1} / p_{t+1}-\delta$ units, which can be sold at a price $p_{t+1}$.

The production of the consumption good $\left(Y_{c t}\right)$ is given by

$$
Y_{c t}=A K_{c t}^{\alpha_{k}}\left(E_{t} N_{c}\right)^{\alpha_{n}}\left(E_{t} L_{c t}\right)^{1-\alpha_{n}-\alpha_{k}}=A E_{t} L_{c t} n_{c t}^{\alpha_{n}} \tilde{k}_{c t}^{\alpha_{k}}, \quad \alpha_{n}, \alpha_{k} \in(0,1),
$$

\footnotetext{
${ }^{8}$ For notational convenience, we do not allow trade in natural resources among individuals living in the same country. Notice that this assumption has no effect on our results because all individuals
} are alike in the model. 
There are, in turn, two technologies to manufacture investment products, but only one of them employs natural resources. These technologies are:

$$
\begin{aligned}
& Y_{x t}=B K_{x t}^{\theta_{k}}\left(E_{t} N_{x}\right)^{\theta_{n}}\left(E_{t} L_{x t}\right)^{1-\theta_{k}-\theta_{n}}=B E_{t} L_{x t} n_{x t}^{\theta_{n}} \tilde{k}_{x t}^{\theta_{k}}, \\
& \bar{Y}_{x t}=B \bar{K}_{x t}^{\theta_{k}}\left(E_{t} \bar{L}_{x t}\right)^{1-\theta_{k}}=B E_{t} \bar{L}_{x t} \tilde{\bar{k}}_{x t}^{\theta_{k}}, \quad \theta_{k}, \theta_{n} \in(0,1) .
\end{aligned}
$$

Above, $E_{t}$ stands for an exogenous level of labor- and specific-factor-augmenting efficiency in period $t$, common to all sectors, that grows at the constant rate $g$; $K_{i t}$ and $L_{i t}$ denote, respectively, the amount of capital and labor devoted in period $t$ to the production of good $i$ by the sectors that employ specific factors; $n_{i t}=$ $N_{i} / L_{i t}, \tilde{k}_{i t}=K_{i t} / E_{t} L_{i t}$, for all $i=x, c ; Y_{x t}$ represents investment-goods production using a specific input in period $t$; and an upper bar $\left(^{-}\right)$denotes variables related to investment-goods production that does not use specific inputs. We shall assume that $N_{c}>0$ and $N_{x}>0$. Moreover, specific-factor technologies have different capital shares, $\alpha_{k} \neq \theta_{k}$.

Denote the fraction of labor employed in the production of good $i$ by $l_{i t}=L_{i t} / L$, and the overall capital stock per efficiency unit of labor by $\tilde{k}_{t}$. Notice that because consumers are alike, the amount of capital own by the representative individual will equal the world's capital-labor ratio. Hence, the constraints on labor and capital can be written as follows:

$$
\begin{gathered}
l_{c t}+l_{x t}+\bar{l}_{x t}=1, \\
l_{c t} \tilde{k}_{c t}+l_{x t} \tilde{k}_{x t}+\bar{l}_{x t} \tilde{\bar{k}}_{x t}=\tilde{k}_{t} .
\end{gathered}
$$

Firms will maximize profits taking as given prices of goods and rental rates on production factors. Taking into account (5), (6), (7), and assuming that capital and labor can freely move across firms, production efficiency implies that

$$
\begin{aligned}
r_{k t} & =\alpha_{k} A n_{c t}^{\alpha_{n}} \tilde{k}_{c t}^{\alpha_{k}-1}=p_{t} \theta_{k} B n_{x t}^{\theta_{n}} \tilde{k}_{x t}^{\theta_{k}-1}=p_{t} \theta_{k} B \tilde{\bar{k}}_{x t}^{\theta_{k}-1}, \\
r_{n c t} & =\alpha_{n} A E_{t} n_{c t}^{\alpha_{n}-1} \tilde{k}_{c t}^{\alpha_{k}}, \\
r_{n x t} & =\theta_{n} A E_{t} n_{x t}^{\theta_{n}-1} \tilde{k}_{x t}^{\theta_{k}}, \\
w_{t} & =\left(1-\alpha_{k}-\alpha_{n}\right) A E_{t} n_{c t}^{\alpha_{n}} \tilde{k}_{c t}^{\alpha_{k}}=\left(1-\theta_{k}-\theta_{n}\right) p_{t} B E_{t} n_{x t}^{\theta_{n}} \tilde{k}_{x t}^{\theta_{k}}=\left(1-\theta_{k}\right) p_{t} B E_{t} \tilde{\bar{k}}_{x t}^{\theta_{k}} .
\end{aligned}
$$

Of course, these equalities will hold only for the technologies that coexist in equilibrium. The following two results establish the firms that open in equilibrium. ${ }^{9}$

\footnotetext{
${ }^{9}$ The proofs of propositions 1 and 2 are contained in appendix A.
} 
Proposition 1 For any wage rate $w_{t}$ and capital rental rate $r_{k t}$, it is profitable to operate a technology that uses specific factors if these are found in the economy in a strictly positive amount.

Proposition 2 Pick $N_{x}>0$. Firms that use the technology that requires only mobile factors will enter the market if and only if

$$
\hat{l}_{x t}>\frac{N_{x}}{L}\left(\frac{1-\theta_{k}-\theta_{n}}{1-\theta_{k}}\right)^{\frac{1-\theta_{k}}{\theta_{n}}}
$$

where $\hat{l}_{x t}$ is the fraction of labor employed in the investment goods sector in equilibrium when only firms that use the specific-factor technology operate. The steady state equilibrium of this employment share is

$$
\hat{l}_{x}^{*}=\frac{\Psi-\frac{\alpha_{k}}{1-\alpha_{k}-\alpha_{n}}}{\frac{\theta_{k}}{1-\theta_{k}-\theta_{n}}-\frac{\alpha_{k}}{1-\alpha_{k}-\alpha_{n}}},
$$

where $\Psi$ is a positive constant defined in Appendix A.

Therefore, an economy that possesses positive endowments of both kinds of natural resources will use the specific-factor technologies at all times. However, whether the technology that requires only mobile inputs is operated or not will depend on the degree of congestion in the use of the natural resource $N_{x}$. If $N_{x} / L$ is sufficiently large, no firm will use that technology. In particular, since $\hat{l}_{x t}$ is positive and smaller than one, no firm will use the non-specific factor technology if

$$
\frac{N_{x}}{L}\left(\frac{1-\theta_{k}-\theta_{n}}{1-\theta_{k}}\right)^{\frac{1-\theta_{k}}{\theta_{n}}}>1 .
$$

Nevertheless, notice that inequality (14) does not impose a big constraint in the domain of $N_{x}$ that supports the coexistence of the three technologies, because whether or not the inequality is satisfied ultimately depends on the units of measurement for the natural resource $N_{x}$. For this reason, we assume that the world economy possesses positive amounts of $N_{x}$ and that these resources are relatively scarce, so condition (14) holds. Therefore, there are firms in the world economy that produce investment goods using the specific-factor technology (6), and firms that use the non-specificfactor technology (7). 


\section{A diversified-production equilibrium}

In this section we analyze the balanced growth equilibrium of a world economy endowed with positive amounts of specific factors, $N_{x}>0$ and $N_{c}>0$, and such that condition (14) holds. So there are firms that operate the non-specific input technology at all times.

In equilibrium, the world economy behaves as a single large and closed economy. Therefore, the world market clearing conditions for final goods are

$$
\begin{aligned}
c_{t} & =A E_{t} l_{c t} n_{c t}^{\alpha_{n}} \tilde{k}_{c t}^{\alpha_{k}}, \\
x_{t} & =B E_{t} l_{x t} n_{x t}^{\theta_{n}} \tilde{k}_{x t}^{\theta_{k}}+B E_{t} \bar{l}_{x t} \tilde{\bar{k}}_{x t}^{\theta_{k}} .
\end{aligned}
$$

Let us denote by an asterisk $\left(^{*}\right)$ steady-state outcomes for the world economy. The consumers' optimality condition (4) and the world's market clearing condition (17) imply

$$
r_{k}^{*}=p^{*}\left[\beta^{-1}(1+g)^{\sigma}+\delta-1\right] .
$$

Defining the wage-capital rental ratio measured in efficiency units as $\tilde{\omega}_{k t}=\frac{w_{t}}{E_{t} r_{k t}}$, the efficiency conditions in production (10) and (13), and (19) determine the optimal amount of capital in efficient-labor units in each industry as a function of this relative factor price:

$$
\begin{aligned}
\tilde{\bar{k}}_{x t} & =\left(\frac{\theta_{k}}{1-\theta_{k}}\right) \tilde{\omega}_{k t}, \\
\tilde{k}_{c t} & =\left(\frac{\alpha_{k}}{1-\alpha_{n}-\alpha_{k}}\right) \tilde{\omega}_{k t}, \\
\tilde{k}_{x t} & =\left(\frac{\theta_{k}}{1-\theta_{k}-\theta_{n}}\right) \tilde{\omega}_{k t} .
\end{aligned}
$$

Using the expression for $r_{k}^{*}$ and condition (10), we obtain the steady-state relative amount of inputs allocated to firms that do not employ specific factors as

$$
\tilde{\bar{k}}_{x}^{*}=\left[\frac{\theta_{k} B}{\beta^{-1}(1+g)^{\sigma}+\delta-1}\right]^{1 /\left(1-\theta_{k}\right)} .
$$

Equations (20) to (23) determine the values of the relative factor prices and capitallabor ratios along the balanced-growth path. Notice that, at the world's diversifiedproduction equilibrium, the steady-state capital-labor ratios across sectors do not depend on the natural resource endowments. This occurs because these ratios are a function of factor intensities and the relative factor price $\tilde{\omega}_{k t}$, but at steady state 
$\tilde{\omega}_{k}^{*}$ is exclusively determined by consumers' preferences and factor intensities in the sector that does not use specific inputs.

We next determine the labor allocations. Conditions (13), (20) and (22) imply that

$$
l_{x t}=\left(\frac{1-\theta_{k}-\theta_{n}}{1-\theta_{k}}\right)^{\frac{1-\theta_{k}}{\theta_{n}}} \frac{N_{x}}{L} .
$$

It states that, along a diversified production equilibrium where all available technologies are used, the amount of labor allocated to the factor-specific production of investment goods is fixed and positively related to the endowment of the immobile resource $N_{x}$, and to the labor intensity in this technology relative to the labor intensity in the production that only uses mobile inputs. Hence, the steady-state labor allocation in the factor-specific production of investment goods, $l_{x}^{*}$, must be given by equation (24) if all available technologies are used. From conditions (13), (20) and (21), we derive the labor allocation to consumption-goods manufacturing as

$$
l_{c t}=\left[\frac{A \alpha_{k}^{\alpha_{k}}\left(1-\alpha_{n}-\alpha_{k}\right)^{1-\alpha_{k}}}{B \theta_{k}^{\theta_{k}}\left(1-\theta_{k}\right)^{1-\theta_{k}}}\left(\frac{\tilde{\omega}_{k t}^{\alpha_{k}-\theta_{k}}}{p_{t}}\right)\right]^{\frac{1}{\alpha_{n}}} \frac{N_{c}}{L} .
$$

So the fraction of labor employed in the $c$-sector depends positively on the specific factor endowment to this sector and inversely on the relative price of investment goods $p_{t}$. The relation between $l_{c t}$ and the relative input price $\tilde{\omega}_{k t}$ will be determined by the sign of $\alpha_{k}-\theta_{k}$. When the production of good $x$ has a larger capital share $\left(\theta_{k}>\alpha_{k}\right)$ that sign will be negative, and vice versa. Finally, once we know the labor allocations to the sectors that employ immobile resources (equations (24) and (25)), the economy's labor constraint (expression (8)) delivers $\bar{l}_{x t}$ as a residual.

Conditions (20) and (23) determine the steady-state relative input price $\omega_{k}^{*}$. The only remaining task to pin down the labor allocations along the balanced-growth path is then deriving the steady-state relative output price. In order to do this, we first obtain the steady-state stock of capital per unit of efficiency labor. Using equations (3), (10), (18) and (19), we can write the steady-state stock of capital as

$$
\tilde{k}^{*}=\left[\frac{\beta^{-1}(1+g)^{\sigma}+\delta-1}{\theta_{k}(\delta+g)}\right]\left(l_{x}^{*} \tilde{k}_{x}^{*}+\bar{l}_{x}^{*} \tilde{\bar{k}}_{x t}^{*}\right) .
$$

Clearly, the stock of capital must be completely split among its different uses given, in relative terms, by equation (9). This market-equilibrium condition determines $p^{*}$. More specifically, combining equations (8), (9), (13), (20) to (23), (24) and (26), we 
find that

$$
p^{*}=\Omega \cdot\left[\frac{\frac{N_{c}}{L}}{1+\gamma \frac{N_{x}}{L}}\right]^{\alpha_{n}},
$$

where $\Omega$ and $\gamma$ are positive constants. ${ }^{10}$

The result is quite intuitive. When the stock of the factor specific to the production of consumption goods rises, the economy devotes relatively more resources to the production of these goods, making investment products relatively more scarce and, as a consequence, more expensive. Exactly the opposite takes place if the amount of the factor specific to the investment-goods sector increases.

Therefore, a larger endowment of any given natural factor raises the amount of labor devoted to the firms that employ it as an input, and decreases the labor allocation to the sector that operates with only mobile inputs. In addition, a larger $N_{x}$ also increases the steady-state labor allocation to the consumption-goods sector. This indirect effect takes place because the increase in the supply of investment goods makes their price to decline, which raises the relative value of the marginal labor productivity in the consumption-goods sector.

\section{Factor endowments and the long-run performance of a small economy}

In this section, we deal with the small open economy that differs from the rest of the world only on the relative endowments of specific factors. We suppose that there is free trade in consumption and investment goods, but that international movements of inputs are prohibited. We show that the steady state income level that it achieves critically depends on the factor intensities of the different industries.

Define $\nu_{i}=N_{i} / L$ as the per capita amount of natural factor $i$ for $i=c, x$. Figure 1 illustrates the two possibilities regarding condition (14) for the small open economy. Panel A shows the effect of an increase in endowment $\nu_{x}$, and Panel B the one of a rise in $\nu_{c}$. The dashed lines correspond to the value of the right-hand side of inequality (14) for different endowments $\nu_{x}$. Notice that the dashed line is independent of $\nu_{c}$. The value of $\hat{l}_{x}$ (left-hand side in (14)) is pinned down by the intersection of two lines

$$
{ }^{10} \Omega=\frac{\frac{A}{B}\left[1+\left(\frac{\alpha_{k}}{1-\alpha_{n}-\alpha_{k}}\right) \frac{\left(1-\theta_{k}\right)(\delta+g)}{(1+g)^{\sigma} \beta^{-1}+\delta-1-\theta_{k}(\delta+g)}\right]^{\alpha_{n}}}{\left(\frac{1-\theta_{k}}{1-\alpha_{n}-\alpha_{k}}\right)^{1-\alpha_{k}}\left(\frac{\theta_{k}}{\alpha_{k}}\right)^{\alpha_{k}}\left(\frac{(1+g)^{\sigma_{\beta}-1}+\delta-1}{\theta_{k} B}\right)^{\frac{\alpha_{k}-\theta_{k}}{1-\theta_{k}}}} \text {, and } \gamma=\frac{\theta_{n}}{1-\theta_{k}-\theta_{n}}\left(\frac{1-\theta_{k}-\theta_{n}}{1-\theta_{k}}\right)^{\frac{1-\theta_{k}}{\theta_{n}}} \text {. }
$$

From the firms optimality conditions follows that the relative price of commodities is a monotone function of $\omega_{k t}$ and $k_{t}$, which guarantees the uniqueness of the equilibrium price at all times. 
that represent the two sides of equation (49) in Appendix B; only the location of one of these two lines, the horizontal one, depends on $\nu_{x}$ and $\nu_{c}$. Clearly, the condition is satisfied if and only if $\hat{l}_{x}$ is to the right of the dashed line. For relatively low values of $\nu_{x}$ and $\nu_{c}$ (thicker horizontal and dashed lines in Panels), condition (14) holds. As $\nu_{x}\left(\nu_{c}\right)$ rises, the dashed line shifts to the right (does not move), and the horizontal solid line moves down (up), making more likely an equilibrium where no firm uses the non-specific-factor technology. As a consequence, for sufficiently large values of $\nu_{x}$ and $\nu_{c}$ (thinner lines), condition (14) does not hold and, hence, the economy only employs two technologies.

For the world economy, fulfilling condition (14) guarantees that the three technologies are operated because, as the non-specific-factor sector hires more labor, marginal productivities vary until the new equilibrium is achieved. For the small economy, however, input prices are exogenous when the three technologies are in use. Hence, condition (14) is necessary but not sufficient for the small economy to be operating with all technologies. Besides fulfilling that condition, the small country needs to have an endowment such that the non-specific-factor sector hires in equilibrium a strictly positive amount of labor. Let us remove the time subscript to denote the balanced-growth values of the small country. The following proposition formally establishes the conditions that determine the firms that open at steady state.

Proposition 3 Assume that the world economy is moving along a balanced growth path. At the steady-state equilibrium of the small economy, firms that use the technology that requires only mobile factors will produce if and only if $\nu_{c}$ and $\nu_{x}$ are sufficiently small to make condition (14) hold and

$$
\nu_{c} / n_{c}^{*}+\nu_{x} / n_{x}^{*}<1
$$

The proof of the proposition is simple. We know that proposition 2 must hold from section 2. In addition, as will be clear later, there is FPE at steady state if the three technologies are used and this implies that $n_{c}=n_{c}^{*}$ and $n_{x}=n_{x}^{*}$. Therefore, inequality (28) just states that $l_{c}+l_{x}<1$.

In what follows, we assume that the relative input endowments of the small economy are such that all technologies are used to produce output at steady state. ${ }^{11}$ This

\footnotetext{
${ }^{11}$ See Appendix $\mathrm{B}$ for the case when all firms use specific factors, and Appendix $\mathrm{C}$ for the case $N_{x}=0$.
} 
Figure 1: Condition (14) and the small open economy

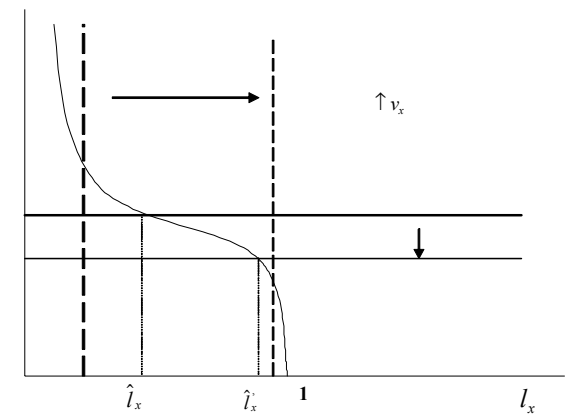

Panel A

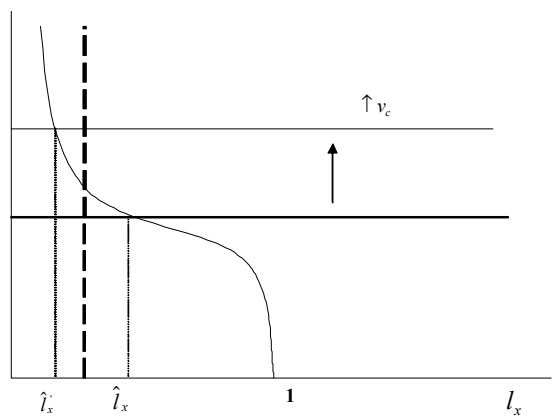

Panel B

is equivalent to supposing that the small economy's specific-factor endowment is not too different from the world economy's. Later in this section, we conduct a numerical exercise that supports that this assumption is not very restricted.

Consumers and firms in the small economy will take as given the international relative price of goods, $p^{*}$, and the domestic rental rates of production factors. Since the small economy shares with the rest of the world its preferences and technologies, its optimality conditions for consumption and production will be also the same. In particular, note that equations (19) to (25) describe also the behavior of any small open economy regardless of its resource endowment, as long as $N_{c}$ is positive. Therefore, under perfectly competitive markets, an open economy that owns resources of the $N_{x}$ and $N_{c}$ types diversifies production and accumulates capital until its rental rate falls down to the world's rate $r_{k}^{*}$, which is by equation (19) exclusively determined by consumers' preferences, the growth rate of technological progress, and $p^{*}$. Along the balanced growth path, expressions (20) to (23) imply that $\bar{k}_{x}=\bar{k}_{x}^{*}, \tilde{\omega}_{k}=\tilde{\omega}_{k}^{*}$, $\tilde{k}_{c}=\tilde{k}_{c}^{*}$, and $\tilde{k}_{x}=\tilde{k}_{x}^{*}$. And from expressions (10) to (13), $n_{c}=n_{c}^{*}, n_{x}=n_{x}^{*}$, $r_{n x t} / E_{t}=r_{n x t}^{*} / E_{t}^{*}, r_{n c t} / E_{t}^{*}=r_{n c t}^{*} / E_{t}^{*}$, and $w_{t} / E_{t}=w_{t}^{*} / E_{t}^{*}$. In sum, in the long run, factor efficiency-price equalization will hold, and the country will be using the same techniques as the rest of the world. Notice that we obtain factor efficiency-price equalization because of the mobile-factors firms, which pin down the relative factor prices for the whole economy. ${ }^{12}$

\footnotetext{
${ }^{12}$ This weak form of FPE is consistent with Trefler's (1993) and Debaere's (2003) empirical evidence.
} 
The overall capital efficiency-labor ratio and labor allocations of the small open economy will depend on its specific-factors endowment and so, in general, they will differ from those of the world economy. Note that the equality $n_{i}=n_{i}^{*}$, for all $i=x, c$, implies that a lower endowment of a given natural resource will make it optimal to allocate a lower fraction of labor to the sector that employs this specific factor. That is, denoting with an asterisk the world's relative endowments, if $\nu_{i}<\nu_{i}^{*}$ then $l_{i}<l_{i}^{*}$ and vice versa.

Regarding the capital stock, we can use equations (8), (9), and (20) to (22) applied to the small economy to get that

$$
l_{c t}=\frac{\theta_{k}\left(1-\alpha_{k}-\alpha_{n}\right)}{\theta_{k}\left(1-\alpha_{n}\right)-\alpha_{k}}\left[1+l_{x} \frac{\theta_{n}}{1-\theta_{k}-\theta_{n}}-\left(\frac{1-\theta_{k}}{\theta_{k}}\right) \frac{\tilde{k}_{t}}{\tilde{\omega}_{k t}}\right],
$$

where $l_{x}$ is the constant labor share employed in investment-goods production with specific inputs when all technologies are used, which we obtained in (24).

At the steady state, the efficiency-wage capital rental ratio equals the international relative factor price, $\tilde{\omega}_{k}=\tilde{\omega}_{k}^{*}$, which is independent of factor endowments. If the difference in relative endowments comes only from the specific-factor in the consumption-goods sector, then $l_{x}=l_{x}^{*}$ and the effect on the long-run capital stock will depend on the relative capital intensities across sectors. In particular, if the investment sector is more capital intensive (i.e., $\left.\theta_{k}\left(1-\alpha_{n}\right)-\alpha_{k}>0\right)$, we have an inverse relationship between $\tilde{k}$ and $\nu_{c}$. That is, $\nu_{c}>\nu_{c}^{*}$ implies that $l_{c}>l_{c}^{*}$ and from (29) we obtain that $\tilde{k}<\tilde{k}^{*}$; and vice versa, $\nu_{c}<\nu_{c}^{*}$ implies that $\tilde{k}>\tilde{k}^{*}$. But if the consumption sector is more capital intensive than the production of investment goods under the non-specific-factors technology, we get the opposite, $\tilde{k}$ is positively related to $\nu_{c}$.

On the other side, when the difference in relative endowments comes only from the specific-factor in the investment-goods sector, we have the following. If $\nu_{x}>\nu_{x}^{*}$, then $l_{x}>l_{x}^{*}$ and, everything else equal, expression (29) implies that $\tilde{k}>\tilde{k}^{*}$; and the other way round if $\nu_{x}<\nu_{x}^{*}$. At first sight, this result seems independent of the input shares across activities. ${ }^{13}$ However, the result rests on the assumption that the capital shares are the same in technologies (6) and (7); which implies that the industry that produces investment goods using specific inputs is more capital intensive than the

\footnotetext{
${ }^{13}$ Notice that because $p^{*}$ is exogenous to the small open economy, $l_{c}$ becomes independent of $N_{x}$ at steady state. Hence, regardless of the factor intensities, $\tilde{k}$ has to move always inversely with $l_{x}$ when $\nu_{x}$ varies in order to keep the equality $l_{c}=l_{c}^{*}$ in equation (29).
} 
one that only employs mobile factors.

In sum, a small economy that differs from the rest of the world only in the amount of $N_{c}$ will have its long-run capital stock above the world's average if and only if (i) its endowment is above the world's average and (ii) the consumption-goods sector is more capital intensive than the production of the investment good that does not use specific-factors. On the contrary, given that we suppose that investment-goods production with specific factors is relatively capital intensive, a larger endowment of the natural input $N_{x}$ will always increase long-run capital.

Changes in the stock of the natural inputs have a similar effect on long-run per capita income $y_{t}$. To see this, notice that using expressions (5) to (7) and (8), we can write the level of GDP per capita $y_{t}=E_{t}\left[l_{c_{t}} y_{c_{t}}+p_{t}\left(l_{x t} y_{x t}+\bar{l}_{x t} \bar{y}_{x t}\right)\right]$ as

$$
y_{t}=E_{t}\left\{l_{c_{t}} A n_{c t}^{\alpha_{n}} \tilde{k}_{c t}^{\alpha_{k}}+p_{t} B\left[l_{x t} n_{x t}^{\theta_{n}} \tilde{k}_{x t}^{\theta_{k}}+\left(1-l_{c_{t}}-l_{x t}\right) \tilde{\bar{k}}_{x t}^{\theta_{k}}\right]\right\} .
$$

When the increase is in $N_{x}, l_{x}$ will rise exactly in the same proportion (to restore $n_{x}=n_{x}^{*}$ ), and this increase will be exactly equal to the decrease in $\bar{l}_{x}$ because $l_{c}$ remains constant. Since all relative uses of inputs will remain unchanged, we have that output in the consumption sector will not change, $d y_{c}=0$, and the change in long-run income will be determined by the following expression:

$$
d y=E_{t} p^{*} B\left(n_{x}^{\theta_{n}} k_{x}^{\theta_{k}}-\tilde{\bar{k}}_{x}^{\theta_{k}}\right) d l_{x}=E_{t} p^{*} B \tilde{\bar{k}}_{x}^{\theta_{k}}\left(\frac{1-\theta_{k}}{1-\theta_{k}-\theta_{n}}-1\right) \frac{d N_{x}}{L} .
$$

The last equality comes from the equalization of labor productivity across sectors and the fact that $d n_{x}=0$. Notice that the denominator and numerator of the first term inside the parentheses equal, respectively, the labor shares in investment-goods production with and without specific factors. Therefore, the sign of $d y / d N_{x}$ is positive because the technology using only mobile inputs has a larger labor share than the specific-factor technology to produce $x$-goods.

Similarly, when the change comes only from the specific factor $N_{c}$, output of firms producing the investment goods with the specific-factor technology will not change, $d y_{x}=0$, and the increase in $y_{c}$ will come at the expense of a reduction in $\bar{y}_{x}$. The increase in $l_{c}$ will be exactly equal to the decrease in $\bar{l}_{x}$. Following the same steps as in (31) we find that the change in overall income per capita is

$$
d y=E_{t} p^{*} B \tilde{\bar{k}}_{x}^{\theta_{k}}\left(\frac{1-\theta_{k}}{1-\alpha_{k}-\alpha_{n}}-1\right) \frac{d N_{c}}{L} .
$$


Thus, an increase in $N_{c}$ will increase overall output if and only if the technology that uses only mobile inputs possesses a larger labor share than the production of $c$-goods (i.e.: $\theta_{k}<\alpha_{k}+\alpha_{n}$ ).

The next proposition summarizes the main results.

Proposition 4 A small open economy that has $N_{x}>0$ and $N_{c}>0$ such that conditions (14) and (28) hold accumulates capital until factor efficiency-price equalization holds. The country's steady-state income level will increase with $N_{x}$, because investment-goods production with specific inputs is more capital intensive than manufacturing with only mobile factors. On the contrary, long-run income will decrease (increase) with $N_{c}$ if the consumption-goods sector has a relatively larger (smaller) labor share.

The lesson from this section is that the impact on the economy's income level of the factor endowment that is specific to a given activity critically depends on the input elasticities of this activity. Note that this implication follows from Rybczynskitype effects which are underlying in the production structure. To illustrate this point, suppose that our small economy is identical to the rest of the world and has already reached the steady state. Then, given the steady state prices, an increase in the small economy's endowment of a specific-factor $N_{i}$ will imply an increase in the share of labor employed by firms that use this specific input and, as a result, an increase in their output. This is done through a shift of labor and capital from firms that use the mobile inputs technology and so it is done at the expense of a fall in their investment-goods output.

In summary, output prices are determined by international markets and this equalizes the input-efficiency-rental rates of the small economy to those of the world economy; as a result the fraction of labor employed by the small economy in an activity that uses a specific factor is solely determined by the world's technique $n_{i}^{*}$ and its own endowment of the specific factor $N_{i}$. Any change in $N_{i}$, everything else constant, implies a reallocation of labor (and capital) between the specific-factor activity $i$ and the activity that only requires mobile inputs. Whether the overall change in aggregate production translates into more income relative to the world's average relies on the relative labor shares between these two production activities. A small-open economy with a larger endowment of a factor specific to an activity that is more capital intensive than the mobile inputs technology will accumulate more capital, 
and will enjoy larger long-run income. But a larger endowment of a factor specific to an activity that is less capital intensive than the mobile inputs technology will lead the economy to a lower capital stock in the long-run that will offset the benefits of the larger endowment if the specific-factor technology has a larger labor elasticity, leading the economy toward a balanced-growth path characterized by smaller income levels. ${ }^{14}$

\subsection{A numerical exercise}

We finish this section with a quantitative measure of the effects on long-run income of changes in $N_{i}$ endowments and differences in labor shares across sectors. We focus on the special case that $N_{x}$ is mineral reserves and $N_{c}$ is land. ${ }^{15}$ To obtain values for the labor shares, we take the US economy as the reference for the world economy. The US average labor shares in Mining and in Agriculture have been, respectively, of 40 percent and 74 percent over the period 1987-2001. ${ }^{16}$ So, we shall assume that $1-\theta_{k}-\theta_{n}$ and $1-\alpha_{k}-\alpha_{n}$ take on 0.40 and 0.74 , respectively.

Notice that the world-economy's income level is not affected by changes in the small economy. Hence, the increase in long-run income relative to the world economy's when specific factor $N_{i}$ rises can be directly determined by the following expression:

$$
\frac{d\left(y / y^{*}\right)}{d v_{i}}=\frac{d y / d v_{i}}{y^{*}}=\frac{\frac{1-\theta_{k}}{s_{i}}-1}{1+\left(\frac{\alpha_{k}+\alpha_{n}-\theta_{k}}{1-\alpha_{k}-\alpha_{n}}\right) l_{c}^{*}+\left(\frac{\theta_{n}}{1-\theta_{k}-\theta_{n}}\right) l_{x}^{*}},
$$

where $s_{i}$ is the labor elasticity in the $N_{i}$ industry, and $l_{i}$ is the fraction of labor employed by the world economy in that sector at steady state $(i=c, x)$. The numerator of this expression follows from (31) for the case $d v_{x}$, and from (32) for the case $d v_{c}$. The denominator follows from (30) taking into account (13). The steady state value $l_{x}^{*}$ is determined from (24), and $l_{c}^{*}$ is computed from (25) taking into account (20) and (23). Because $l_{x}^{*}$ and $l_{c}^{*}$ are invariant to changes in the small economy, expression (33)

\footnotetext{
${ }^{14}$ See Proposition 5 in Appendix B for the effects of specific-factor endowments when FPE does not hold.

${ }^{15}$ Defining and providing a consistent measure of all types of $N_{i}$ endowments and their shares in sectorial production are beyond the scope of this article.

${ }^{16}$ Data obtained from the Annual Industry Accounts published on line by the Bureau of Economic Analysis at http://www.bea.gov. Labor shares are computed as compensations of employees plus proprietor's income divided by GDP net of indirect taxes. Notice that this measure should be seen as an upper bound, since proprietor's income includes labor as well as some land and capital rents.
} 
Table 1: Changes in relative long-run income

\begin{tabular}{ccc}
\hline \hline$\alpha_{k}=0.16, \alpha_{n}=0.10$ & $\frac{d\left(y / y^{*}\right)}{d v_{x}}$ & $\frac{d\left(y / y^{*}\right)}{d v_{c}}$ \\
\hline & & \\
$\theta_{k}=0.4, \theta_{n}=0.2$ & 0.597 & -0.226 \\
$\theta_{k}=0.3, \theta_{n}=0.3$ & 0.784 & -0.057 \\
$\theta_{k}=0.2, \theta_{n}=0.4$ & 0.931 & 0.076 \\
\hline \hline
\end{tabular}

defines a constant derivative. The ultimate reason is that, under international FPE, input rental prices in the small economy are independent of domestic endowments.

To obtain numerical predictions from (33), we need to calibrate all its parameters. We give a value of 0.64 to $p^{*}$. This price is the US average price of equipment relative to consumption in 1985 reported by Eaton and Kortum (2001). We normalize $B$ to one and obtain the value for $A$ consistent with the equilibrium price $p^{*}=0.64$, assuming that the world's relative endowments are $\nu_{c}^{*}=2$ and $\nu_{x}^{*}=0.025$. The value $\nu_{c}^{*}=2$ is very close to the 1.9 arable-land-hectares per worker (average for the period 1967-1996) given for the U.S. by the Food and Agricultural Organization of the United Nations (FAO). The value of $\nu_{x}^{*}=0.025$, in turn, is chosen so that condition (14) holds. ${ }^{17}$ We have also computed relative income variations for other relative endowment values such that (14) holds, and obtain no significative changes in the results. The rest of parameters take standard values, they are calibrated so that the steady state interest rate is 6 percent. In particular, we have assumed that $\beta=0.98, \sigma=1, \delta=0.06$, and $g=0.02$.

The results are reported in Table 1 , and correspond to a land share $\left(\alpha_{n}\right)$ of 10 percent in the value added of consumption goods. A land share of 5 percent generated almost the same predictions and they are not reported. Results are obtained maintaining the labor shares constant in both sectors, for different elasticities in the investment-goods sector.

The Table shows something that we already know: what really matters for the sign of the $N_{c}$ effect, given a labor share in the consumption sector of 0.74 , is the value of $\theta_{k}$. When $\theta_{k}$ is below 0.26 , the labor share in the non-specific factor industry is larger than in the consumption sector, and then an increase in $N_{c}$ translates into

\footnotetext{
${ }^{17}$ As we mentioned in section 2 , we can really choose any amount for $\nu_{c}^{*}$ and $\nu_{x}^{*}$ because their values ultimately depend on the units of measurement. This does not mean though that there is no discipline in the exercise. These arbitrarily chosen values affect the domain $\left(\nu_{x}, \nu_{c}\right)$ that is compatible with the coexistence of the three technologies in the small economy. See below.
} 
an income improvement. We also observe that the effect of changes in $N_{i}$ decreases with $\theta_{k}$, and that the effect of $N_{x}$ on income is stronger (absolute value) than the effect of $N_{c}$. The main reason is that the effect is driven by differences in the laborelasticity between the specific-factor activities and the non-specific-factor sector, and this difference is always smaller in the case of consumption-goods production. Finally, the table says that a one-unit increase in $v_{x}$ endowment implies an increase in relative income between $0.59\left(\theta_{k}=0.4\right)$ and $0.93\left(\theta_{k}=0.2\right)$. Whereas the induced variation in relative income by the same increase in $v_{c}$ is between $-0.23\left(\theta_{k}=0.4\right)$ and 0.08 $\left(\theta_{k}=0.2\right)$.

Let us focus on the case $\theta_{k}=0.4$, which represents an empirically supported value for the economy's aggregate capital share. For this value of $\theta_{k}$, proposition 3 implies that the maximum values of $\nu_{c}$ and $\nu_{x}$ for which the three technologies are operated in the small economy are 2.37 if $\nu_{x}=\nu_{x}^{*}$ and 0.55 if $\nu_{c}=\nu_{c}^{*}$, respectively. Hence, the model predicts that, ceteris paribus, a nation with a $\nu_{c}$ endowment of 0.36 would be about 46 percent richer than a nation with $\nu_{c}=2.36$. Whereas a country with a $\nu_{x}$ endowment of 0.51 would be 30 percent richer than a nation with $\nu_{x}=0.01$. We then conclude from the numerical experiment that increases in specific factor endowments can have positive or negative Rybczynski-type effects on the long-run income of small open economies, and that these effects can be substantial.

A final issue that we must address is whether the domain that sustains an equilibrium in which the three technologies coexist, that is, $\left(\nu_{c}, \nu_{x}\right)$ with $\nu_{c} \in(0,2.37)$ and $\nu_{x} \in(0,0.55)$ is very restrictive. The answer is that it is not. On the one hand, the FAO data show that 98 percent of nations possess a number of arable-land hectares per worker (averages for the period 1967-1990) below 2.37, and the minimum number is 0.002 . The values of $\nu_{x}$, on the other, greatly depend on the type of mineral at which we look and the units of measurement. For example, looking at the numbers across nations published for 1997 by the Energy Information Administration (US Department of Energy, International Energy Annual 2002), the minimum of mineral reserves is zero, and the maximum is 0.014 million short tons per worker and year if we refer to coal extraction and 1.64 thousand barrels per worker and day if we refer to crude oil. 


\section{Discussion of results}

The model predicts that, under incomplete specialization, possessing a relatively high aggregate endowment of fixed specific inputs such as natural resources can be a blessing or a curse in terms of long-run income, depending on the relative labor shares between the specific factor industry and that one employing only mobile factors. Larger endowments have a positive direct effect on long-run income but their induced effect on capital accumulation can be positive or negative depending on the relative capital intensities across sectors. For example, if the industry using only mobile inputs is the most labor intensive activity, then larger endowments of specific inputs of any kind have a positive effect on capital accumulation and on long run income. But if the production of investment goods using specific inputs is relatively capital intensive and the production of consumption goods is the most labor intensive activity, then a larger $N_{x}$ leads to a higher long-run capital and income level, whereas a bigger $N_{c}$ generates a lower steady-state capital and income. Therefore, the model can explain why some nations that seem to have similar resource endowments can show very different income levels.

Findings are conditioned on the assumptions made. One that is clearly critical for our results is the existence in equilibrium of at least a technology that exclusively operates with mobile factors. This assumption permits the model to reconcile specificfactors frameworks with the evidence presented by Trefler (1993) in favor of (efficiency adjusted) FPE across nations. However, there might be still open economies that are far away from the average, and in which factor prices are not equalized. Appendix $\mathrm{B}$ shows that, when all firms use specific inputs and there is no FPE, having a larger labor share in the sector that uses the rising specific factor is still a necessary condition, but no longer sufficient to obtain a negative impact of the larger endowment on long-run income. Now, sufficiency requires this sector to be sufficiently less capital intensive.

We have also assumed that countries possess resources specific to both industries. In that scenario, specialization is not possible. However, recent empirical studies such as Debaere and Demiroglu (2003) and Schott (2003) find evidence that suggests that some countries are specialized. In Appendix C, we show that when countries do not possess resources specific to one sector, production specialization is possible, and that under specialization a larger natural endowment always leads the economy 
to higher capital stocks and income levels in the long-run. The intuition is simple. Under specialization, a larger specific-factor endowment no longer induces a resource stealing effect on other sectors. As a consequence, for a sufficiently large specificinput endowment, the specialized country can accumulate enough capital so that its long run income will be above the world's average.

The findings presented in proposition 4 imply that the model can also predict overtaking episodes along the adjustment path. Suppose two small nations that begin their development path at time zero with the same levels of capital per capita $k_{0}<k_{c}^{*}$ (if investment goods are more capital intensive), or $k_{0}<k_{x}^{*}$ (if consumption goods are more capital intensive), and the same levels of efficiency $E_{0}$, labor $L$ and $N_{x}>0$. Moreover, one economy shares the same relative specific-factor endowments as the average world economy, $\nu_{i}=\nu_{i}^{*}(i=c, x)$, but the other one owns a smaller $N_{c}{ }^{18}$ It is straightforward that, at the initial time, the country with a smaller natural-input stock will have a lower income level because it has the same amounts of the other three inputs. From proposition 4, we know that the natural resource-poorer economy will accumulate capital faster and, at some point along the development path, will overtake the resource-richer economy if the consumption-goods sector has a higher labor share, ending up having higher income levels.

Allowing for differences in the initial levels of efficiency across countries has no effect on the qualitative results presented in the paper, provided that these differences are not too large. But cross-nation productivity disparities would certainly affect the threshold of the specific-factor endowment that determines when long-run income is above the world's average. For example, if a small economy starts up with a lower efficiency level, it will need a smaller endowment of the input specific to the industry with the largest labor share to be able to overcome the world-economy's long-run income. This is so because in our model efficiency grows at the same exogenous rate everywhere and initial productivity differences will persist.

Some of our results have the flavor of the immiserizing-growth literature. In a

\footnotetext{
${ }^{18}$ Actually, the initial capital-labor ratio $k_{0}$ should be a function of the other factor endowments. In order to generate overtaking, we need that the resource-poorer economy enjoys a smaller initial income level. Equation (32) says that when $k_{0}$ is endogenous this occurs if $\theta_{k}<\alpha_{k}+\alpha_{n}$. We could think that the economies start at time zero from a preindustrial steady-state in which firms use different technologies than in the new long-run situation towards which the development path converges. In particular, preindustrial technologies make relatively bigger use of animal power and people's labor. As a consequence, capital intensities in the preindustrial era are smaller, and more similar across sectors than in technologies (5) to (7) so that the above inequality holds.
} 
classical paper, Bhagwati (1958) showed that a reduction in income from worsened terms of trade can exceed income generated by an augmented capital stock, so that growth immiserizes. ${ }^{19}$ In our case the terms of trade of the small economy are fixed, but the possibility of a lower long-run income associated to a higher specific-factor endowment arises when the larger endowment of this specific input affects negatively the long run stock of the accumulable factor.

More specifically within our Walrasian model, laissez faire leads agents to invest in the consumption-goods sector when the stock of its specific factor rises. Unfortunately, if the production of investment goods is more capital intensive, these shortrun gains can come at a cost of lower future capital and income levels. A benevolent central planner might then be tempted to intervene if present gains are more than outweighed by future losses; in that case, an optimal policy must imply a domestic rate of return on capital above its international level so that the steady state level of capital associated to a larger stock of $N_{c}$ is sufficiently higher than its laissez faire value. Note that in our Walrasian world economy, the small country faces a relative price of investment goods that does not respond to changes in local conditions. In autarky, an increase in $N_{c}$ has a positive effect on the relative price of investment goods and on the domestic return on capital, so growth never inmmiserizes. That is, the rigidity of the world's relative price with respect to local conditions acts as a negative externality for the small open economy.

It is therefore clear that besides the positive implications of the model, it also has normative ones. If the goal of policymakers is to permanently increase income, subsidizing the exploitation or accumulation of factors that are specific to less capitalintensive activities can be mistaken. This is not only relevant for natural resources. We can think for example, as in Eaton and Gersovitz (1981), about an increase in managerial skills brought into the domestic economy by foreign managers through foreign direct investment. Our results imply that, only if the skills/knowledge brought by the foreign managers are not specific to one sector and, in addition, spill over other activities, an improvement in the economy's log-run income level will be guaranteed. For this reason, before implementing this type of policies, it seems important to study

\footnotetext{
${ }^{19}$ More recently special attention has been devoted to the 'harmful' consequences of natural resource discoveries. Such discoveries cause a reallocation of resources from manufacturing and agriculture into services (often non-tradeble urban services) that put upward presure on real wages in terms of tradable goods and so imply a decline in external competitiveness that more than outweighs the initial boom in income (see Edwards and Van Wijnbergen (1992)).
} 
the input intensities in the different industries and whether factors are mobile across sectors. More case studies in line with the work of Kohli (1993) for the US economy but including natural resources should be most helpful.

\section{Conclusion}

The paper has presented an open-economy version of the two-sector neoclassical growth model in which investment- and consumption-goods are produced using fixed specific factors. Our model differs from the dynamic specific-factors model of international trade in that we allow capital to move freely across sectors and have a third technology to manufacture investment goods that only requires intersectorally mobile factors. It is the inclusion of this technology what induces factor-price equalization across open economies that produce within the diversification cone.

The model predicts that nations that diversify production but possess a relatively low endowment of factors can outperform countries with a larger natural-resource endowment. The reason is that a larger specific-input endowment in a less capitalintensive sector drives the economy towards a long-run allocation with a lower capital stock, which can completely offset the positive effects of the larger resource stock. Quite the contrary, if two nations only differ in their input endowment specific to a relatively capital-intensive industry, the resource-richer nation also becomes the per capita output-richer economy.

We have argued above that these results possess both positive and normative implications. In addition, our model has also a clear implication for empirical research. The above findings suggest that in order to disentangle the impact of fixed specificfactors and, in particular, natural resources on income levels and growth rates, it is important to carry out the investigation at the sectoral level. 


\section{Appendix}

\section{A Proofs}

Proof of proposition 1. Suppose that a technology that requires an immobile factor is not used. The firms that have access to this technology will like to open if they make profits for the prices (say $\hat{r}_{k}, \hat{w}_{t}, \hat{r}_{n x}, \hat{r}_{n c}$ and $\hat{p}$ ) that prevail in the equilibrium where the economy is located. In particular, given $N_{c}>0$, a firm in the consumption-goods sector chooses $K_{c t}$ and $L_{c t}$ to maximize its profits $\Pi_{c t}$, which is equivalent to maximizing

$$
A\left(\frac{K_{c t}}{E_{t} N_{c}}\right)^{\alpha_{k}}\left(\frac{L_{c t}}{N_{c}}\right)^{1-\alpha_{k}-\alpha_{n}}-r_{k t} \frac{K_{c t}}{E_{t} N_{c}}-w_{t} \frac{L_{c t}}{E_{t} N_{c}}-r_{n c t} \frac{1}{E_{t}} .
$$

The maximum level of profits, per efficiency unit of the specific factor, then equals

$$
\frac{\Pi_{c t}}{E_{t} N_{c}}=\alpha_{n} A^{\frac{1}{\alpha_{n}}}\left(\frac{1-\alpha_{k}-\alpha_{n}}{w_{t} / E_{t}}\right)^{\frac{1-\alpha_{k}-\alpha_{n}}{\alpha_{n}}}\left(\frac{\alpha_{k}}{r_{k t}}\right)^{\frac{\alpha_{k}}{\alpha_{n}}}-r_{n c t} / E_{t} .
$$

In an equilibrium in which these type of firms do not operate, it must be true that $\hat{r}_{n c t}=0$. Hence, in expression (35) maximum profits are strictly positive, for all $t$. Given that this problem is identical to the one of the investment-goods sector, firms that use specific factors will always have incentives to open.

Proof of proposition 2. These firms' profits equal

$$
\bar{\Pi}_{x t}=p_{t} B \bar{K}_{x t}^{\theta_{k}}\left(E_{t} \bar{L}_{x t}\right)^{1-\theta_{k}}-r_{k t} \bar{K}_{x t}-w_{t} \bar{L}_{x t} .
$$

At the maximum, it must hold that

$$
\max _{\substack{0 \leq \bar{K}_{x t} \leq K_{t} \\ 0 \leq \bar{L}_{x t} \leq L}} \bar{\Pi}_{x t}=\bar{K}_{x t}\left[r_{k t}\left(\frac{1-\theta_{k}}{\theta_{k}}\right)-\frac{w_{t}}{E_{t}}\left(\frac{r_{k t}}{\theta_{k} p_{t} B}\right)^{\frac{1}{1-\theta_{k}}}\right],
$$

since $\left(E_{t} \bar{L}_{x t} / \bar{K}_{x t}\right)^{1-\theta_{k}}=r_{k t} / p_{t} B \theta_{k}$. Let $\hat{r}_{k t}, \hat{w}_{t}$, and $\hat{p}_{t}$ be the equilibrium market prices when only firms that use specific inputs operate. Given $E_{t}, \hat{r}_{k t}, \hat{w}_{t}$, and $\hat{p}_{t}$, firms that do not use natural resources will want to enter the market if and only if they make profits, that is, if and only if

$$
\hat{p}_{t} B>\left(\frac{\hat{r}_{k}}{\theta_{k}}\right)^{\theta_{k}}\left(\frac{\hat{w}_{t} / E_{t}}{1-\theta_{k}}\right)^{1-\theta_{k}}
$$

From optimality conditions (10) and (13) for investment-goods producers that use specific factors, expression (38) becomes

$$
\hat{p}_{t} B>\left(\frac{\hat{p}_{t} \theta_{k} B n_{x t}^{\theta_{n}} \tilde{k}_{x t}^{\theta_{k}-1}}{\theta_{k}}\right)^{\bar{\theta}_{k}}\left[\frac{\left(1-\theta_{k}-\theta_{n}\right) \hat{p}_{t} B n_{x t}^{\theta_{n}} \tilde{k}_{x t}^{\theta_{k}}}{1-\theta_{k}}\right]^{1-\theta_{k}},
$$

which reduces to 


$$
\hat{l}_{x t}>\left(\frac{1-\theta_{k}-\theta_{n}}{1-\theta_{k}}\right)^{\frac{1-\theta_{k}}{\theta_{n}}} N_{x} / L .
$$

The variable $\hat{l}_{x t}$ corresponds to the world's equilibrium when the non-specific factor technology is not used. At steady state, it is possible to give a closed-form solution to $\hat{l}_{x t}$, call it $\hat{l}_{x}^{*}$. In particular, $\hat{l}_{x}^{*}$ is determined by the following set of equations:

$$
\begin{gathered}
\theta_{k} B \nu_{x}^{\theta_{n}}\left(\hat{l}_{x}^{*}\right)^{-\theta_{n}}\left(\frac{\theta_{k}}{1-\theta_{k}-\theta_{n}} \omega_{k}^{*}\right)^{\theta_{k}-1}=(1+g)^{\sigma} \beta^{-1}-1+\delta, \\
(g+\delta) k^{*}=B \nu_{x}^{\theta_{n}}\left(\hat{l}_{x}^{*}\right)^{1-\theta_{n}}\left(\frac{\theta_{k}}{1-\theta_{k}-\theta_{n}} \omega_{k}^{*}\right)^{\theta_{k}}, \\
p^{*}=\frac{A \alpha_{k}^{\alpha_{k}}\left(1-\alpha_{k}-\alpha_{n}\right)^{1-\alpha_{k}} \nu_{c}^{* \alpha_{n}}\left(\hat{l}_{x}^{*}\right)^{\theta_{n}} \omega_{k}^{* \alpha_{k}-\theta_{k}}}{B \theta_{k}^{\theta_{k}}\left(1-\theta_{k}-\theta_{n}\right)^{1-\theta_{k}} \nu_{x}^{* \theta_{n}}\left(1-\hat{l}_{x}^{*}\right)^{\alpha_{n}}}, \\
l_{x}^{*}=\frac{k^{*}-\frac{\alpha_{k} \omega_{k}^{*}}{1-\alpha_{k}-\alpha_{n}}}{\frac{\theta_{k} \omega_{k}^{*}}{1-\theta_{k}-\theta_{n}}-\frac{\alpha_{k} \omega_{k}^{*}}{1-\alpha_{k}-\alpha_{n}}} .
\end{gathered}
$$

Equation (41) comes from (10) and (19), equation (42) follows from (18), (43) from (10), and (44) from (8), (9), (21) and (22), evaluated at the steady state when $\bar{l}_{x}=0$.

From the three equations (41), (42) and (44), we can obtain closed solutions for the three unknowns $k^{*}, \omega_{k}^{*}$ and $l_{x}^{*}$. After that, we can solve for $p^{*}$ using (43). These solutions are:

$$
k^{*}=\Psi \omega_{k}^{*}, \quad \omega_{k}^{*}=\Psi_{1}, \quad l_{x}^{*}=\Psi_{2},
$$

where $\Psi, \Psi_{1}$ and $\Psi_{2}$ are positive constants given by

$$
\begin{gathered}
\Psi=\frac{\alpha_{k} /\left(1-\alpha_{k}-\alpha_{n}\right)}{1-\frac{(g+\delta)\left(\theta_{k}\left(1-\alpha_{n}\right)-\alpha_{k}\left(1-\theta_{n}\right)\right)}{\left(\beta^{-1}(1+g)^{\sigma}-1+\delta\right)\left(1-\alpha_{k}-\alpha_{n}\right)}} \\
\Psi_{1}=\frac{\left(1-\theta_{k}-\theta_{n}\right)}{\theta_{k}}\left(\frac{\theta_{k} B \nu_{x}^{\theta_{n}} \Psi_{2}^{-\theta_{n}}}{(1+g)^{\sigma} \beta^{-1}-1+\delta}\right)^{\frac{1}{1-\theta_{k}}} \\
\Psi_{2}=\frac{\Psi-\frac{\alpha_{k}}{1-\alpha_{k}-\alpha_{n}}}{\frac{\theta_{k}}{1-\theta_{k}-\theta_{n}}-\frac{\alpha_{k}}{1-\alpha_{k}-\alpha_{n}}} .
\end{gathered}
$$




\section{B The small economy when all firms use specific factors}

Obviously, proposition 4 holds as long as $\bar{l}_{x}>0$. Above some value of $N_{x}$ and $N_{c}$, the economy will achieve a corner solution in which firms that use the technology that only requires mobile factors will shut down. Suppose first that condition (40), or equivalently (14), does not hold, that is

$$
\hat{l}_{x}<\left(\frac{1-\theta_{k}-\theta_{n}}{1-\theta_{k}}\right)^{\frac{1-\theta_{k}}{\theta_{n}}} N_{x} / L, \quad \forall t .
$$

Under condition (47), the country will still accumulate capital until its rental rate is the same as in the world economy, but the rest of factor prices will remain different.

At the steady state, the firms' efficiency conditions (10) (taking $\bar{l}_{x t}=\bar{k}_{x t}=0$ ), (20) and (22) imply that

$$
\tilde{\omega}_{k}=\left(\frac{1-\theta_{k}-\theta_{n}}{1-\theta_{k}}\right) n_{x}^{\theta_{n} /\left(1-\theta_{k}\right)} \tilde{\omega}_{k}^{*}
$$

Notice that $n_{x}$ in (48) equals $\left(N_{x} / L\right) / l_{x}$. Which in turn implies that $\tilde{\omega}_{k}>\tilde{\omega}_{k}^{*}$ under condition (47). Since the capital labor ratios in both sectors are proportional to the relative factor price $\tilde{\omega}_{k}$, it follows that the country will be using in the long-run more capital intensive techniques than the other economies, $\tilde{k}_{x}>\tilde{k}_{x}^{*}$ and $\tilde{k}_{c}>\tilde{k}_{c}^{*}$, and that $w>w^{*}$.

If, on the other hand, condition (14) holds but condition (28) does not, we have the opposite scenario. From expression (48), $\tilde{\omega}_{k}<\tilde{\omega}_{k}^{*}$. As a consequence, the country will use in the long-run less capital intensive techniques than the world economy, $\tilde{k}_{x}<\tilde{k}_{x}^{*}$ and $\tilde{k}_{c}<\tilde{k}_{c}^{*}$, and $w<w^{*}$.

From equations (10) and (13), we can obtain the following relationship between the labor allocation and the specific-factors endowment:

$$
\left(\frac{1-\alpha_{k}-\alpha_{n}}{1-\theta_{k}-\theta_{n}}\right) \frac{\left(\alpha_{k} / r_{k t}\right)^{\frac{\alpha_{k}}{1-\alpha_{k}}}}{\left(\theta_{k} / r_{k t}\right)^{\frac{\theta_{k}}{1-\theta_{k}}}} \frac{\left(A \nu_{c}^{\alpha_{n}}\right)^{\frac{1}{1-\alpha_{k}}}}{\left(p^{*} B \nu_{x}^{\theta_{n}}\right)^{\frac{1}{1-\theta_{k}}}}=\frac{\left(1-l_{x t}\right)^{\frac{\alpha_{n}}{1-\alpha_{k}}}}{l_{x t}^{\frac{\theta_{n}}{1-\theta_{k}}}}
$$

Therefore, when only the technologies that use specific factors operate, $\hat{l}_{x t}$ varies inversely with $\nu_{c}=N_{c} / L$, and positively with $\nu_{x}=N_{x} / L$ and $\tilde{k}_{x t}$. The last relationship follows because $r_{k t}$ and $\tilde{k}_{x t}$ are inversely related (see equation (10)). Notice also that the right side of (49) describes a strictly decreasing function of $l_{x}$ that goes from infinity to zero as $l_{x}$ goes from zero to one, and that the left side is a positive constant independent of $l_{x}$. Therefore, there exists a unique $l_{x}$ that solves (49). In turn, this solution evaluated at the steady state and (48) will determine $\widetilde{\omega}_{k}$.

Along the balanced-growth path, $r_{k t}=r_{k}^{*}$ for all $t$. Expression (49) then implies that a larger $\nu_{c}$ decreases the steady-state allocation of labor $l_{x}$ and, therefore, increases $l_{c}$. Because the allocation of labor to the investment-goods sector goes down, the capital-labor ratio in this activity must rise to maintain the interest rate invariant (see expression (10)). The increase of $\tilde{k}_{x}$, in turn, implies that $\tilde{k}_{c}$ also rises because, by optimality conditions (10) and (13), the ratio of $\tilde{k}_{c}$ to $\tilde{k}_{x}$ is constant. The same type of reasoning says that an increase in $\nu_{x}$ decreases $l_{c}$ and raises $l_{x}, \tilde{k}_{c}$ and $\tilde{k}_{x}$. Equation (10) also implies that if $\tilde{k}_{i}$ rises, so does $n_{i}$, for all $i=x, c$. 
Hence, unlike in the case with the three firm types, an increase in any specificfactor endowment now may rise the capital-labor ratios of both production activities. Ceteris paribus, this contributes to raise income. However, even in this case, the final aggregate capital stock can still diminish (remember equation (9)) if too much labor is reallocated to the less capital intensive sector, and lead the economy to a lower long-run output level.

To see this, we can use production functions (5) and (6), conditions (8) and (10) with $\bar{l}_{x t}=0$, and expressions $(21)$ and $(22)$, to write the steady-state income per capita level when all firms use specific factors as

$$
y_{t}=E_{t}\left[p^{*} n_{x}^{\theta_{n}}\left(\frac{\theta_{k}}{r_{k}^{*}}\right)^{\theta_{k}}\right]^{\frac{1}{1-\theta_{k}}}\left[\frac{\left(1-\theta_{k}-\theta_{n}\right)+l_{x}\left(\theta_{k}+\theta_{n}-\alpha_{k}-\alpha_{n}\right)}{1-\alpha_{k}-\alpha_{n}}\right] .
$$

As we saw in the previous paragraph, when the relative endowment $\nu_{x}$ rises, the steady-state labor allocation $l_{x}$ and the value of $n_{x}$ increase. Then, expression (50) implies that if the investment-goods sector has a larger labor share $\left(\theta_{k}+\theta_{n}<\alpha_{k}+\alpha_{n}\right)$, the steady-state income level can decrease with $\nu_{x}$. In the same way, an increase in $\nu_{c}$ provokes a decline in $l_{x}$ and a larger $n_{x}$. So an increase in $\nu_{c}$ can still imply a decrease in long-run income if the consumption-goods sector is sufficiently more labor intensive than the $x$-sector. In all other cases, the effect of a larger amount of any specific-factor is positive.

For example, the following are sufficient conditions for a negative long-run income effect. From equation (50), we can easily get that, if $N_{c}$ increases and $d N_{x}=0$, $d y_{t}<0$ iff $\theta_{k}+\theta_{n}-\alpha_{k}-\alpha_{n}>\theta_{n} / l_{x}$. Given that $l_{x}$ declines with $\theta_{n}$, for all $\theta_{k}>\alpha_{k}+\alpha_{n}$, there exists a sufficiently low $\theta_{n}$ such that $d y_{t} / d N_{c}<0$.

Also from expression (50), it can be shown that, when $N_{x}$ rises and $d N_{c}=0$, $d y_{t} / d N_{x}<0$ iff

$$
\left(\frac{\nu_{x}}{l_{x}}\right)^{-1} \frac{\left(1-\theta_{k}-\theta_{n}\right)+l_{x}\left(\theta_{k}+\theta_{n}-\alpha_{k}-\alpha_{n}\right)}{\left(1-\theta_{k}-\theta_{n}\right)-\left(\frac{1-\theta_{k}-\theta_{n}}{\theta_{n}}\right) l_{x t}\left(\theta_{k}+\theta_{n}-\alpha_{k}-\alpha_{n}\right)}<\frac{d l_{x}}{d \nu_{x}} .
$$

Now, take into account that the optimal allocation to $l_{x}$, given by condition (49), implies that

$$
\frac{d l_{x}}{d \nu_{x}}=\frac{\nu_{x}^{-1}}{l_{x}^{-1}+\frac{\alpha_{n}\left(1-\theta_{k}\right)}{\theta_{n}\left(1-\alpha_{k}\right)}\left(1-l_{x}\right)^{-1}} .
$$

The last two expressions imply that $d y_{t} / d N_{x}<0$ iff

$$
\frac{\left(1-\theta_{k}-\theta_{n}\right)+l_{x}\left(\theta_{k}+\theta_{n}-\alpha_{k}-\alpha_{n}\right)}{\left(1-\theta_{k}-\theta_{n}\right)-\left(\frac{1-\theta_{k}-\theta_{n}}{\theta_{n}}\right) l_{x t}\left(\theta_{k}+\theta_{n}-\alpha_{k}-\alpha_{n}\right)}<\frac{1}{1+\frac{\alpha_{n}\left(1-\theta_{k}\right)}{\theta_{n}\left(1-\alpha_{k}\right)}\left(\frac{l_{x}}{1-l_{x}}\right)} .
$$

The right-hand side of this condition goes to one as $\alpha_{n}$ goes to zero, whereas the left-hand side is always smaller than one if $\alpha_{k}+\alpha_{n}>\theta_{k}+\theta_{n}$. Therefore, for all $\alpha_{k}>\theta_{k}+\theta_{n}$, there exists a value of $\alpha_{n}$ sufficiently small such that the last condition holds and then $d y_{t} / d N_{x}<0$.

The following proposition states the main findings.

Proposition 5 Fix $p_{t}=p^{*}$, and $N_{c}, N_{x}>0$ such that condition (14) or condition (28) do not hold at steady-state. The country's steady-state capital-labor ratios will be above the ones of the world economy if inequality (14) holds; they will be below 
otherwise. In addition, an increase in a specific-factor stock raises the small country's steady-state income level if the sector to which the input is specific has a lower labor share or it has a larger labor share but labor shares across sectors are sufficiently similar. The effect is negative if the other sector is sufficiently more capital intensive.

In sum, when international FPE does not hold in the long run because all firms produce with specific factors, a negative impact of a larger specific-factor endowment is still possible. The difference with respect to the case in which long-run FPE holds is that having a larger labor intensity in the sector that uses the rising specific factor is no longer sufficient to obtain a negative impact of the larger endowment on long-run income. Now, sufficiency requires this sector to be sufficiently more labor intensive.

\section{Investment-goods production without specific inputs}

When the country does not find in its territory natural resources specific to the investment-goods production activity, production takes place using only technologies (5) and (7). Given that $N_{x}$ equals zero, specialization in consumption-goods production is a possible equilibrium outcome. The next proposition establishes conditions under which this is the case.

Proposition 6 Fix $N_{x}=0$. The investment-goods sector will open if and only if

$$
p_{t}>\frac{A}{B}\left(\frac{\alpha_{k}}{\theta_{k}}\right)^{\theta_{k}}\left(\frac{1-\alpha_{k}-\alpha_{n}}{1-\theta_{k}}\right)^{1-\theta_{k}} \nu_{c}^{\alpha_{n}} \tilde{k}_{t}^{\alpha_{k}-\theta_{k}}
$$

where $\tilde{k}_{t}$ denotes the equilibrium stock of capital per efficiency unit of labor when only consumption-goods are manufactured.

The proof to this proposition follows the same logic as the one for proposition 2 above. For this reason it is omitted. Implicitly, expression (53) determines a minimum price above which it becomes profitable for investment-goods producers to enter the market. This minimum price depends on the relative endowment of the specific factor $\nu_{c}$, the capital/labor ratio, and factor intensities, let us denote it by $p_{\min }\left(\tilde{k}_{t} ; \nu_{c}\right)$. The country then specializes in the production of consumption goods if $p_{\min }\left(\tilde{k}_{t} ; \nu_{c}\right)$ is greater than or equal to $p_{t}$. More specifically, closing the investmentgoods sector becomes more appealing as $\nu_{c}$ increases and as $\tilde{k}_{t}$ and $p_{t}$ decline or, in other words, as the consumption-goods sector becomes relatively more productive.

Suppose first the situation where the small country's factor endowments are such that it produces only consumption goods, remaining specialized in the long run. The economy accumulates capital through imports of investment goods, with $\tilde{k}_{t}=\tilde{k}_{c t}$ and $l_{c t}=1$ for all $t$, until the domestic rate of return on capital reaches $r_{k}^{*}$. At that point, the firms' efficiency conditions (10), (11) and (13), and the world's production steady state techniques, $n_{c}^{*}$ and $\tilde{k}_{c}^{*}$, pin down $\tilde{k}$ as

$$
\tilde{k}=\left[\left(\nu_{c} / \nu_{c}^{*}\right) l_{c}^{*}\right]^{\frac{\alpha_{n}}{1-\alpha_{k}}} \tilde{k}_{c}^{*} .
$$

The same conditions imply that unlike in the diversified-production scenario, factor efficiency-prices in the specialized economy do not converge to the ones of the rest of the world. In particular, the relative factor price $\tilde{\omega}_{k}$ goes up with $\nu_{c}$.

However, for (54) to be a steady-state equilibrium, it must be true that it is not profitable to operate in the investment-goods sector. That is, that condition (53) 
does not hold when capital is given by (54). Substituting (54) into (53), we can easily find that the country will not diversify production in the long-run if its relative endowment of the factor specific to the production of consumption goods satisfies

$$
\nu_{c} \geq \nu_{c}^{*} / l_{c}^{*}=n_{c}^{*} .
$$

Under (55), expression (54) implies that $\tilde{k} \geq \tilde{k}_{c}^{*}$. Moreover, long-run capital is now positively related to $N_{c}$. The reason is that an increase in the specific-factor endowment no longer induces a resource stealing effect on other sectors. Unlike in the diversified-production scenario, when the country specializes its long-run income level rises with the endowment of the specific factor. As a consequence, for $\nu_{c}$ sufficiently large, the specialized country can accumulate enough capital so that its long run income, $y=A \nu_{c}^{\alpha_{n}} \tilde{k}^{\alpha_{k}}$, will be above the world's average.

If, on the other hand, the country has $\nu_{c}<n_{c}^{*}$, it produces inside the diversification cone at the steady state, and it is straightforward that factor prices and income then behave as in proposition 4 .

The following proposition summarizes these results.

Proposition 7 A small open economy with $N_{x}=0$ and $\nu_{c}<n_{c}^{*}$ diversifies production at the steady state, and its long-run income and factor prices behave as in proposition 3. If, on the other hand, its endowment $\nu_{c}$ is larger or equal than $n_{c}^{*}$, the economy specializes in consumption-goods production in the long-run, its efficiencyfactor prices do not converge to the world's prices, and its income level along the balanced-growth path increases with the endowment specific to the consumption sector. 


\section{References}

Bhagwati, J., "Immiserizing growth: a geometrical note", Review of Economic Studies, 25: 201-205, 1958.

Brock, P.L., and S.J. Turnovsky, "The growth and welfare consequences of differential tariffs," International Economic Review 34:765-794, 1993.

Debaere, P., "Relative factor abundance and trade", Journal of Political Economy 111(5): 589-610, 2003.

Debaere, P., and U. Demiroglu, "On the similarity of country endowments," Journal of International Economics 59(1):101-136, 2003.

Dinopoulos, E., and P. Segerstrom, "The dynamic effects of contingent tariffs," Journal of International Economics 47:191-222, 1999.

Eaton, J., "A dynamic specific-factors model of international trade," Review of Economic Studies 54:325-338, 1987.

Eaton, J., "Foreign public capital flows", chapter 25 in Chenery and Srinivarsan Eds., Handbook of Development Economics, Vol. II, North Holland, 1992.

Eaton, J., and M. Gersovitz, "Debt with Potential Repudiation: Theoretical and Empirical Analysis," Review of Economic Studies 48:289-309, 1981.

Eaton, J. and S. Kortum, "Trade in Capital Goods," European Economic Review 45:1195-1235, 2001.

Edwards, S., and S. Van Wijbergen, "Disequilibrium and structural adjustment", chapter 28 in Chenery and Srinivarsan Eds., Handbook of Development Economics, Vol. II, North Holland, 1992.

Galor, O., O. Moav and D. Vollrath, "Divergence and Overtaking: Land Abundance as a Hurdle for Education Reforms," mimeo, Brown University, 2002.

Galor, O., and A. Mountford, "Trade, Demographic Transition, and the Great Divergence: Why are a Third of People Indian or Chinese?" mimeo, Brown University, 2003.

Gollin, D., S.L. Parente and R. Rogerson, "Structural Transformation and CrossCountry Income Differences," mimeo, Arizona State University, 2002.

Gylfason, T., "Natural Resources, Education and Economic Development," European Economic Review 45:847-859, May 2001.

Hansen, G.D., and E.C. Prescott, "Malthus to Solow," American Economic Review, 1205-1217, September 2002.

Jones, R.W., and J.P. Neary, "The positive theory of international trade," in R.W. Jones and P.B. Kenen, eds., Handbook on International Economics (North Holland, Amsterdam), 2nd edition, 1988.

Kögel, T., and A. Prskawetz, "Agricultural Productivity Growth and Escape from the Malthusian Trap," Journal of Economic Growth 6:337-357, 2001.

Kohli, U., "U.S. Technology and the Specific-Factors Model," Journal of International Economics 34:115-136, February 1993. 
Markusen, J.R., and R. Manning, "Long-run production frontiers for the Jones specific-factors model with optimal capital accumulation", in W.J. Ethier, E. Helpman and J.P. Neary, eds, Theory, Policy and Dynamics in International Trade: Essays in honor of Ronald Jones, 1993.

Matsuyama, K., "Agricultural productivity, comparative advantage, and economic growth," Journal of Economic Theory 58: 317-334, 1992.

Oniki, H., and H. Uzawa, "Patterns of Trade and Investment in a Dynamic Model of International Trade," Review of Economic Studies, 1965.

Rassekh, F., and H. Thompson, "Adjustment in general equilibrium: Some industrial evidence," Review of International Economics 5:20-31, 1997.

Ricardo, D., On the Principles of Political Economy and Taxation (John Murray, London), 1817. Reprinted in P. Sraffa, ed., The Works and Correspondence of David Ricardo, Vol. 1 (Cambridge University Press, Cambridge).

Sachs, J.D., and A.M. Warner, "The curse of natural resources," European Economic Review 45:827-838, May 2001.

Schott, P.K., "One Size Fits All? Heckscher-Ohlin Specialization in Global Production," American Economic Review 93(3):686-708, 2003.

Trefler, D., "International factor price differences: Leontief was right!" Journal of Political Economy 101(6):961-987, 1993.

World Bank, "Expanding the measure of wealth: Indicators of environmentally sustainable development," Environmentally sustainable development studies and monographs series no. 7, 1994. 


\section{Appendix for referees, not for publication}

These notes are intended to be helpful to the reader carrying out the refereeing job.

They derive some of the analytical expressions contained in the paper.

\section{Equation (4)}

It follows directly from the F.O.C's of the consumer's problem, which imply that

$$
\begin{aligned}
c_{t+1}^{\sigma} /\left(\beta c_{t}^{\sigma}\right) & =\lambda_{t} / \lambda_{t+1}, \\
\lambda_{t} p_{t} & =\lambda_{t+1}\left[r_{k t+1}+p_{t+1}(1-\delta)\right],
\end{aligned}
$$

where $\lambda_{t}$ is the Lagrange multiplier of the budget constraint in period $t$.

\section{Equation (24)}

From (13), (20) and (22), we can write

$$
\left(1-\theta_{k}-\theta_{n}\right) p_{t} B E_{t} n_{x t}^{\theta_{n}}\left[\left(\frac{\theta_{k}}{1-\theta_{k}-\theta_{n}}\right) \tilde{\omega}_{k t}\right]^{\theta_{k}}=\left(1-\theta_{k}\right) p_{t} B E_{t}\left[\left(\frac{\theta_{k}}{1-\theta_{k}}\right) \tilde{\omega}_{k t}\right]^{\theta_{k}}
$$

And then, since $n_{x t}=\left(N_{x} / L\right) / l_{x}$, we obtain (24).

\section{Equation (25)}

From conditions (13), (20) and (21), we write

$$
\left(1-\alpha_{k}-\alpha_{n}\right) A E_{t} n_{c t}^{\alpha_{n}}\left[\left(\frac{\alpha_{k}}{1-\alpha_{n}-\alpha_{k}}\right) \tilde{\omega}_{k t}\right]^{\alpha_{k}}=\left(1-\theta_{k}\right) p_{t} B E_{t}\left[\left(\frac{\theta_{k}}{1-\theta_{k}}\right) \tilde{\omega}_{k t}\right]^{\theta_{k}} .
$$

We then use the fact that $n_{c t}=\left(N_{c} / L\right) / l_{c}$, and get $(25)$.

\section{Equation (27)}

Combining (13), and (20) to (23) at steady state

$$
\begin{aligned}
& \left(1-\alpha_{k}-\alpha_{n}\right) A E_{t} n_{c t}^{\alpha_{n}}\left[\left(\frac{\alpha_{k}}{1-\alpha_{n}-\alpha_{k}}\right)\left(\frac{1-\theta_{k}}{\theta_{k}}\right)\left(\frac{\theta_{k} B}{\beta^{-1}(1+g)^{\sigma}+\delta-1}\right)^{\frac{1}{1-\theta_{k}}}\right]^{\alpha_{k}} \\
= & \left(1-\theta_{k}-\theta_{n}\right) p_{t} B E_{t} n_{x t}^{\theta_{n}}\left[\left(\frac{\theta_{k}}{1-\theta_{k}-\theta_{n}}\right)\left(\frac{1-\theta_{k}}{\theta_{k}}\right)\left(\frac{\theta_{k} B}{\beta^{-1}(1+g)^{\sigma}+\delta-1}\right)^{\frac{1}{1-\theta_{k}}}\right]^{\theta_{k}} .
\end{aligned}
$$

Using (24), this simplifies to

$$
p^{*}=\frac{A}{B}\left(\frac{N_{c} / L}{l_{c}^{*}}\right)^{\alpha_{n}}\left(\frac{1-\alpha_{k}-\alpha_{n}}{1-\theta_{k}}\right)^{1-\alpha_{k}}\left(\frac{\alpha_{k}}{\theta_{k}}\right)^{\alpha_{k}}\left(\frac{\theta_{k} B}{\beta^{-1}(1+g)^{\sigma}+\delta-1}\right)^{\frac{\alpha_{k}-\theta_{k}}{1-\theta_{k}}} .
$$


We need to solve for $l_{c}^{*}$. Equations (8), (9) and (26) imply that

$$
l_{c}^{*} \tilde{k}_{c}^{*}+l_{x}^{*} \tilde{k}_{x}^{*}+\left(1-l_{c}^{*}-l_{x}^{*}\right) \tilde{\bar{k}}_{x}^{*}=\left[\frac{\beta^{-1}(1+g)^{\sigma}+\delta-1}{\theta_{k}(\delta+g)}\right]\left[l_{x}^{*} \tilde{k}_{x}^{*}+\left(1-l_{c t}-l_{x t}\right) \bar{k}_{x}^{*}\right] .
$$

Using (20) to (22), we can get:

$$
\begin{aligned}
& l_{c}^{*}\left(\frac{\alpha_{k}\left(1-\theta_{k}\right)}{\left(1-\alpha_{n}-\alpha_{k}\right) \theta_{k}}-1\right)+l_{x}^{*}\left(\frac{1-\theta_{k}}{1-\theta_{k}-\theta_{n}}-1\right)+1 \\
= & {\left[\frac{\beta^{-1}(1+g)^{\sigma}+\delta-1}{\theta_{k}(\delta+g)}\right]\left[l_{x}^{*}\left(\frac{1-\theta_{k}}{1-\theta_{k}-\theta_{n}}-1\right)-l_{c t}+1\right] . }
\end{aligned}
$$

The steady state value of $l_{c}^{*}$ is then

$$
\begin{aligned}
l_{c}^{*} & =\frac{\left(\frac{\beta^{-1}(1+g)^{\sigma}+\delta-1}{\theta_{k}(\delta+g)}-1\right) \frac{\theta_{n}}{1-\theta_{k}-\theta_{n}}\left(\frac{1-\theta_{k}-\theta_{n}}{1-\theta_{k}}\right)^{\frac{1-\theta_{k}}{\theta_{n}}} \frac{N_{x}}{L}+\left(\frac{\beta^{-1}(1+g)^{\sigma}+\delta-1}{\theta_{k}(\delta+g)}-1\right)}{\frac{\alpha_{k}\left(1-\theta_{k}\right)}{\left(1-\alpha_{n}-\alpha_{k}\right) \theta_{k}}+\left(\frac{\beta^{-1}(1+g)^{\sigma}+\delta-1}{\theta_{k}(\delta+g)}-1\right)} \\
& =\frac{1+\frac{\theta_{n}}{1-\theta_{k}-\theta_{n}}\left(\frac{1-\theta_{k}-\theta_{n}}{1-\theta_{k}}\right)^{\frac{1-\theta_{k}}{\theta_{n}}} \frac{N_{x}}{L}}{\frac{\alpha_{k}\left(1-\theta_{k}\right)}{\left(1-\alpha_{n}-\alpha_{k}\right) \theta_{k}}\left[\frac{\beta^{-1}(1+g)^{\sigma}+\delta-1-\theta_{k}(\delta+g)}{\theta_{k}(\delta+g)}\right]^{-1}+1} .
\end{aligned}
$$

Putting together the above expressions for $p^{*}$ and $l_{c}^{*}$, we obtain (27).

\section{Equation (29)}

From (8), (9), and (20) to (22),

$$
\begin{aligned}
l_{c t} & =\frac{\tilde{k}_{t}-\tilde{\bar{k}}_{x t}-l_{x t}\left(\tilde{k}_{x t}-\tilde{\bar{k}}_{x t}\right)}{\tilde{k}_{c t}-\tilde{\bar{k}}_{x t}}=\frac{\frac{\tilde{k}_{t}}{\tilde{\tilde{\omega}}_{k t}}-\frac{\theta_{k}}{1-\theta_{k}}-l_{x t}\left(\frac{\theta_{k}}{1-\theta_{k}-\theta_{n}}-\frac{\theta_{k}}{1-\theta_{k}}\right)}{\frac{\alpha_{k}}{1-\alpha_{n}-\alpha_{k}}-\frac{\theta_{k}}{1-\theta_{k}}} \\
& =\frac{\left(\frac{1-\theta_{k}}{\theta_{k}}\right) \frac{\tilde{k}_{t}}{\tilde{\omega}_{k t}}-1-l_{x t}\left[\frac{\theta_{k}\left(1-\theta_{k}\right)}{\left(1-\theta_{k}-\theta_{n}\right) \theta_{k}}-1\right]}{\frac{\alpha_{k}\left(1-\theta_{k}\right)}{\left(1-\alpha_{n}-\alpha_{k}\right) \theta_{k}}-1}=\frac{\left(\frac{1-\theta_{k}}{\theta_{k}}\right) \frac{\tilde{k}_{t}}{\tilde{\omega}_{k t}}-1-\frac{\theta_{n}}{1-\theta_{k}-\theta_{n}} l_{x t}}{\frac{\alpha_{k}-\theta_{k}\left(1-\alpha_{n}\right)}{\left(1-\alpha_{n}-\alpha_{k}\right) \theta_{k}}} .
\end{aligned}
$$

This is (29).

\section{Equation (33)}

Taking into account (13) we can write (30) for the world's economy at the steady state as

$$
y_{t}^{*}=E_{t} p^{*} B \tilde{\bar{k}}_{x}^{* \theta_{k}}\left[\left(\frac{1-\theta_{k}}{1-\alpha_{k}-\alpha_{n}}\right) l_{c}^{*}+\left(\frac{1-\theta_{k}}{1-\theta_{k}-\theta_{n}}\right) l_{x}^{*}+\left(1-l_{c}^{*}-l_{x}^{*}\right)\right] .
$$

This is the denominator in (33). The numerator is (31) for the case $d N_{x}$, with $s_{x}=1-\theta_{k}-\theta_{n}$, and the numerator is (32) for the case $d N_{c}$, with $s_{c}=1-\alpha_{k}-\alpha_{n}$. 


\section{Equation (52)}

We can rewrite equation (49) as

$$
\Gamma \nu_{c}^{\frac{\alpha_{n}}{1-\alpha_{k}}} l_{x t}^{\frac{\theta_{n}}{1-\theta_{k}}}=\nu_{x}^{\frac{\theta_{n}}{1-\theta_{k}}}\left(1-l_{x t}\right)^{\frac{\alpha_{n}}{1-\alpha_{k}}} ;
$$

where $\Gamma$ is a constant and represents all terms in (49) that are not explicitly shown above. Differentiating this expression and assuming $d \nu_{c}=0$, we can get the following expression:

$$
\begin{aligned}
& {\left[\Gamma \nu_{c}^{\frac{\alpha_{n}}{1-\alpha_{k}}}\left(\frac{\theta_{n}}{1-\theta_{k}}\right) l_{x t}^{\frac{\theta_{n}}{1-\theta_{k}}-1}+\left(\frac{\alpha_{n}}{1-\alpha_{k}}\right)\left(1-l_{x t}\right)^{\frac{\alpha_{n}}{1-\alpha_{k}}-1} \nu_{x}^{\frac{\theta_{n}}{11-\theta_{k}}}\right] d l_{x t} } \\
= & \left(1-l_{x t}\right)^{\frac{\alpha_{n}}{1-\alpha_{k}}}\left(\frac{\theta_{n}}{1-\theta_{k}}\right) \nu_{x}^{\frac{\theta_{n}}{1-\theta_{k}}-1} d v_{x} .
\end{aligned}
$$

Now substituting the first expression into the second one, we obtain:

$$
\begin{aligned}
& {\left[\left(\frac{\theta_{n}}{1-\theta_{k}}\right) l_{x t}^{-1}+\left(\frac{\alpha_{n}}{1-\alpha_{k}}\right)\left(1-l_{x t}\right)^{-1}\right] \nu_{x}^{\frac{\theta_{n}}{1-\theta_{k}}}\left(1-l_{x t}\right)^{\frac{\alpha_{n}}{1-\alpha_{k}}} d l_{x t} } \\
= & \left(1-l_{x t}\right)^{\frac{\alpha_{n}}{1-\alpha_{k}}}\left(\frac{\theta_{n}}{1-\theta_{k}}\right) \nu_{x}^{\frac{\theta_{n}}{1-\theta_{k}}-1} d v_{x} .
\end{aligned}
$$

This simplifies to equation (52). 